\title{
New lease of life for Lawrence Berkeley Laboratory
}

Berkeley, California

LAWRENCE Berkeley Laboratory (LBL) is booming into the $1990 \mathrm{~s}$. As one of the chosen centres for the Department of Energy (DoE) Human Genome Project. a DoE designated superconductivity research centre and home for the new $\$ 100$ million Advanced Light Source synchrotron, the national laboratory is embarking on a wave of activity and growth.

As if to belie its origins as a nuclear physics centre, laboratory director David Shirley has embarked on a reorganization plan giving the life sciences a much more prominent position under Paul Silverman. now appointed associate director. The human genome project should carry LBL's life sciences programme out of its traditional field of radiation studies and into the mainstream of modern biology.

The DoE's decision to pursue a project to map and sequence the human genome has led to questions as to why it has chosen to become involved in a large-scale biology project. But Shirley says that conducting the genome project in a DoE laboratory with DoE money will protect other biomedical research, such as that sponsored by the National Institutes of Health (NIH).

DoE's decision to name LBL as one of two new centres for human genetic studies is nevertheless something of a surprise. Lawrence Livermore National Laboratory had been more frequently mentioned as a participant, largely on the strength of its work on chromosome sorting, an important first step in dividing the genome into manageable subunits.

But John Hearst, of LBL's chemical biodynamics division and a chemistry professor at the University of California at Berkeley, says LBL has unique advantages that make it a logical place for the project. The laboratory has extensive computing facilities and the technological skills that will be needed in producing a physical map and ultimately a sequence of the 3,500 million base pairs that make up the human genome. It is also within walking distance of the university campus where basic biological sciences are winning renewed attention, adding scientific credibility to DoE's efforts in biology.

Silverman says LBL intends to use the new yeast artificial chromosome (YAC) technology to clone large DNA fragments - from 400 to 1,000 kilobases. Restriction enzymes such as NotI, which cut DNA strands at infrequent combinations of bases, have only recently made it possible to obtain such large pieces of DNA. The new technique of pulsed field gel electrophoresis provides a tool for analysing the large fragments. Charles Cantor, one of the developers of the new technique, is being recruited from Columbia to head LBL`s genome project.

Jack Bartley, deputy director of the genome project, acknowledges that there may be pitfalls in pursuing such a combination of new technology, but he says that early investigations seem to confirm that the large cloned fragments can be reliably reproduced. While $\mathrm{LBL}$ pursues the YAC technology, Los Alamos and Lawrence Livermore National Laboratories will continue to work on the smaller 40 -kilobase cosmid libraries.

LBL has also encouraged other campuses of the University of California system to submit grant applications to DoE for genome work, all of which would be coordinated at Berkeley.

Silverman is reluctant to discuss budget figures until Congress approves DoE's 1988 budget. DoE has requested $\$ 12$ million for genome activities in the fiscal year 1988, and there is sufficient confidence that enough of that will make its way to LBL to enable Silverman to begin recruiting staff for the project.

LBL's energy science programme is also growing, as plans get under way for the Advanced Light Source (ALS), which will generate $\mathrm{X}$-ray beams for research and diagnostic uses. It will be the laboratory's first new high-energy facility to be built in over 30 years.

The X-rays generated by the synchrotron will range in energy from 1 to 1,000 $\mathrm{eV}$. Jay Marx, programme director for the project, said the ALS will complement the higher energy 7-GeV synchrotron planned for Argonne National Laboratory. While the Argonne synchrotron will be more suited to solid-state physics, Marx said Berkeley's ALS will be ideal for the imaging of atoms in biological materials, since water is transparent to X-rays with energy in the $40-\mathrm{eV}$ range. Among other planned applications for the ALS are gas-phase chemistry - as, for example, using X-rays to measure extremely small concentrations of gases - and materials science applications such as determining the orientation of catalytic molecules on surfaces

As a national laboratory facility, Marx said, the ALS will be open to all researchers whose projects pass peer review. The plans allow for the construction of seven beam lines on present budgets, but the laboratory is looking for companies or research groups wishing to build extra beam lines, at a cost of $\$ 0.5-2$ million per line. Marx expects the ALS to be a "gold mine for science and technology", adding that every synchrotron source of the handful already in operation is oversubscribed with users.

The ALS project received $\$ 9.5$ million in start-up money from the DoE in fiscal year 1987, and has asked for $\$ 18$ million for 1988 and $\$ 30$ million for 1989 . Construction is due to begin in 1988 and to be completed in 1992.

For the first time in 20 years, other new construction is under way at LBL. Two buildings nearing completion will house the Center for Advanced Materials, whose members have been scattered between the laboratory and the adjacent University of California campus since the centre's establishment in 1983. Plans are in place for the 2-acre building which will house the Advanced Light Source, and more construction is on the horizon, to house the human genome and superconductivity research centers.

The DoE designated Superconductivity Research Center at LBL, which will study thin film superconductors, is still in the planning stages, without a building or a guaranteed budget. Director Shirley says that the LBL's major worry on all three projects is a concern shared by all US science: whether Congress will commit the funds these projects require.

Marcia Barinaga \& Joseph Palca

\section{India at last gets US supercomputer}

\section{New Delhi}

AFTER two years of negotiations, the United States has agreed to export a supercomputer to India for use in monsoon research. An agreement was signed last month, a few days before Prime Minister Rajiv Gandhi's scheduled meeting with President Reagan in Washington.

Although the president had approved the sale of a supercomputer to India in 1985, the negotiations were held up because of differences over safeguard conditions and the type of supercomputer to be supplied. The agreement signed in New Delhi by John Gunther Dean, the US ambassador, and K.P.S. Menon, the Indian Foreign Secretary, does not specify the model. India had requested a Cray XMP-24, the type sold to US allies. According to a Foreign Office spokesman, the United States has agreed to supply any one of the less advanced versions - the Cray XMP-1, XMP-14 or CDC-2O5 - but not the twin processor XMP-24.

The Indian Department of Science and Technology is likely to choose the XMP14. The Indian government is said to have sought assurances from the United States that the computer will be upgraded later. India has also agreed to safeguards and curbs on the use made of the computer, but no details have been published.

K.S. Jayaraman 